In der Rubrik „Literatur kompakt" werden die wichtigsten Originalarbeiten aus der internationalen Fachliteratur referiert.

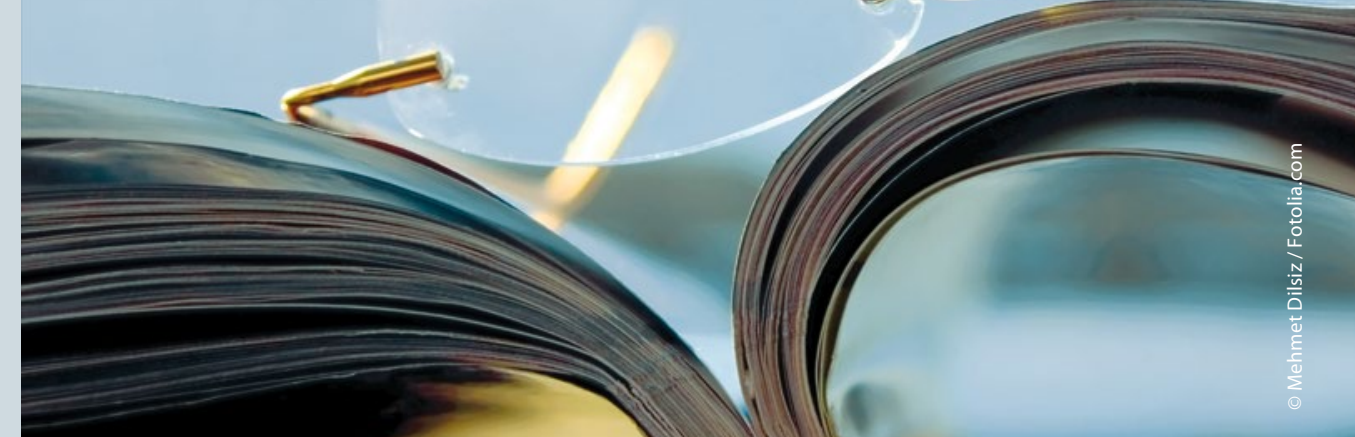

\section{Erdnuss-Immuntherapie mit anhaltender Wirkung}

\section{Frühzeitiger mehrjähriger Erdnusskonsum kann bei Hochrisikokindern die Entwicklung einer Allergie gegen die Hülsenfrucht verhindern. Die Schutzwir- kung scheint auch eine anschließende „Erdnuss-Pause“ zu überdauern.}

$\mathrm{D}$ ass eine orale Toleranzinduktion gegen Erdnuss möglich ist, hat die LEAP-Studie gezeigt: Kinder mit hohem Risiko dafür hatten bis zu ihrem fünften Geburtstag seltener eine Erdnussallergie entwickelt, wenn sie vom ersten Lebensjahr an wöchentlich mindestens sechs Gramm Erdnüsse gegessen hatten (Erdnussgruppe). Im Provokationstest zeigten nur $1,9 \%$ von ihnen eine Reaktion. Unter den Kindern, die in den ersten fünf Lebensjahren auf Erdnüsse verzichtet hatten (Vermeidungsgruppe), er- reichte die Allergiequote $13,7 \%$. Ob die durch Erdnussverzehr erzeugte Immuntoleranz von Dauer ist, wurde nun in einer Anschlussstudie untersucht.

550 der ursprünglich 628 Studienteilnehmer, davon 270 aus der Erdnussgruppe, beteiligten sich an der ein Jahr dauernden Folgestudie, in der alle Kinder auf den Verzehr von Erdnüssen verzichten sollten. Wurden, unabhängig von der Compliance, alle Kinder ausgewertet, dann reagierten bei der abschließenden oralen Provokation 4,8\% aus der

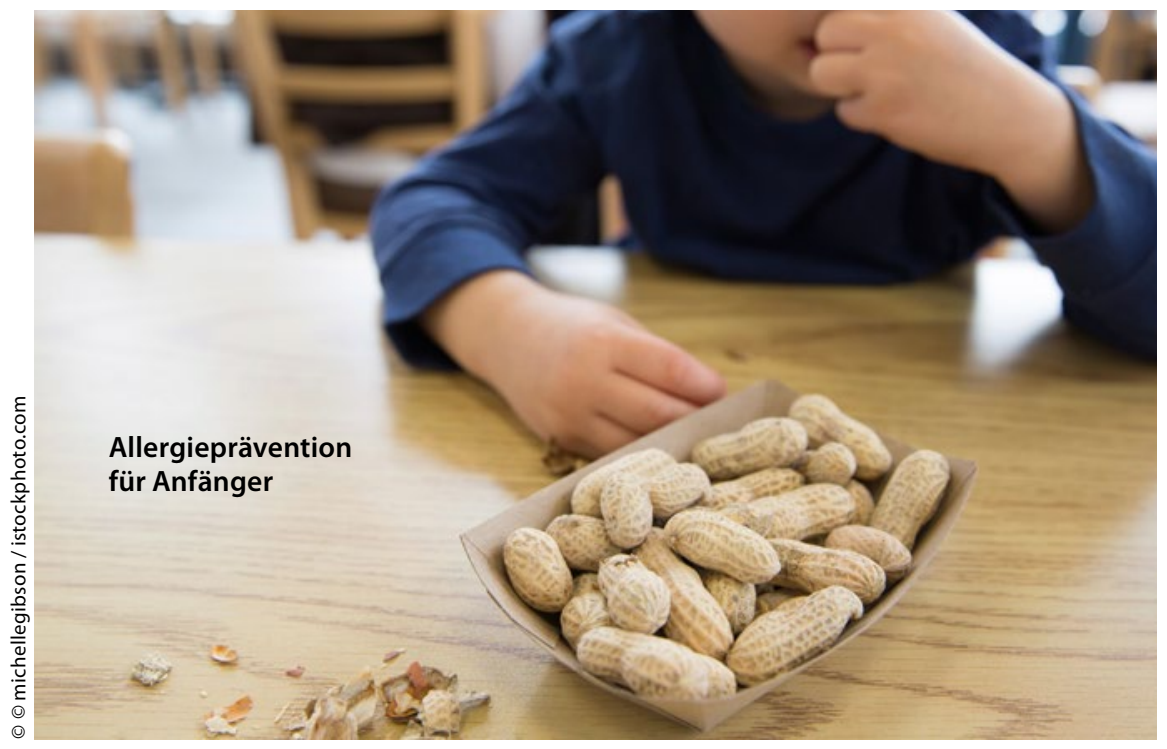

Erdnussgruppe und 18,6\% aus der Vermeidungsgruppe. Damit waren in beiden Gruppen im Laufe des Jahres drei weitere Kinder zu Erdnussallergikern geworden.

Allerdings hatten sich in der Erdnussgruppe nur 69,3\% der Kinder an das Erdnussverbot gehalten, in der Vermeidungsgruppe waren es $90,4 \%$ gewesen. Doch auch wenn man die Analyse auf diejenigen Kinder beschränkte, die tatsächlich ein Jahr lang abstinent gewesen waren (maximal $18 \mathrm{~g}$ Erdnüsse in Portionen von maximal $2 \mathrm{~g}$ ), ergab sich ein hochsignifikanter Vorteil für die Erdnussgruppe. Die Allergierate betrug hier 2,1\% gegenüber 19,2\% in der Kontrollgruppe.

Die erhaltene Schutzwirkung zeigte sich auch an den Antikörpertitern: Die IgE-Spiegel gegen das Erdnuss-MajorAllergen Ara h 2 waren in der Erdnussgruppe weiterhin signifikant niedriger und die Konzentrationen von erdnussspezifischem IgG4 weiterhin signifikant höher als in der Vermeidungsgruppe.

Fazit: Die Ergebnisse der LEAP-Folgestudie zeigen, dass vier Jahre Erdnusskonsum ausreichen, um eine stabile Immuntoleranz gegenüber Erdnuss zu induzieren. Zwar lässt sich aufgrund der Studie keine Aussage über die notwendige Dauer der oralen Immuntherapie machen. Die Studienautoren gehen allerdings davon aus, dass für eine dauerhafte Wirkung wie bei der spezifischen Immuntherapie gegen Gräserpollen oder Insektengift eine längere Behandlung erforderlich ist.

Dr. Beate Schumacher 